\title{
Jogos cooperativos e a promoção da cooperação na educação infantil
}

\author{
Marilicia Witzler Antunes Ribeiro Palmieri \\ Universidade Estadual de Londrina - Londrina - PR
}

\begin{abstract}
Resumo
O presente artigo analisa em nível microgenético como duas professoras de um Centro Filantrópico de Educação Infantil do município de Londrina-PR promovem ou inibem a cooperação entre seus alunos, a partir da proposta dos jogos cooperativos, tendo como referencial teórico e metodológico as contribuições da perspectiva sociocultural construtivista de desenvolvimento humano. A análise microgenética de episódios interativos videogravados mostrou que as professoras se orientaram para o objetivo de incentivar/estimular a participação coletiva das crianças no contexto dos jogos cooperativos. Valoriza-se a proposta dos jogos cooperativos na educação infantil como um recurso educativo essencial para as professoras integrarem práticas lúdicas de cooperação e de solidariedade e gerar processos de negociação de conflitos e a internalização de valores construtivos (ajuda mútua, colaboração, empatia), para que a criança venha a co-construir novos significados sobre a sua participação em brincadeiras.
\end{abstract}

Palavras-chave: Jogos; cooperação; educação infantil.

\section{Cooperative games and the promotion of cooperation in preschool education}

\begin{abstract}
This article analyzes in microgenetic level as two teachers of a Philanthropic Center of Child Education of Londrina-PR promote or inhibit cooperation among their students, from the proposal of cooperative games, having as theoretical and methodological reference the perspective of contributions sociocultural constructivist human development. The microgenetic analysis of interactive videotaped showed that teachers were oriented towards the objective of encouraging / stimulating the collective participation of children in the context of cooperative games. The proposal of cooperative games in early childhood education is valued as an essential educational resource for teachers integrate playful practices of cooperation and solidarity and generate conflict negotiation processes and the internalization of constructive values (mutual aid, cooperation, empathy) to the child will frame new meanings on their participation in play.
\end{abstract}

Keywords: Games; cooperation; childhood education.

\section{Juegos cooperativos y la promoción de la cooperación en la educación infantil}

\begin{abstract}
Resumen
El presente artículo analiza en nivel micro genético cómo dos profesoras de un Centro Filantrópico de Educación Infantil del municipio de LondrinaPR promueven o inhiben la cooperación entre sus alumnos, a partir de la propuesta de los juegos cooperativos, teniendo como referencial teórico y metodológico las contribuciones de la perspectiva sociocultural constructivista de desarrollo humano. El análisis micro genética de episodios interactivos vídeo-gravados mostró que las profesoras se orientaron para el objetivo de incentivar/estimular la participación colectiva de los niños en el contexto de los juegos cooperativos. Se valorala propuesta de los juegos cooperativos en la educación infantil como un recurso educativo esencial para las profesoras integrar prácticas lúdicas de cooperación y de solidaridad y generar procesos de negociación de conflictos y la internalización de valores constructivos (ayuda mutua, colaboración, empatía), para que el niño venga a construir nuevos significados sobre su participación en juegos.
\end{abstract}

Palabras-clave: Juegos; cooperación; educación infantil. 


\section{Introdução}

A complexidade das transformações pelas quais passa a sociedade moderna tem exigido cada vez mais uma compreensão interdisciplinar do fenômeno da interdependência social em suas dimensões subjetiva e histórico-cultural. O reflexo dessas transformações se traduz em consequências concretas observáveis nas diversas formas de vida social, pois ao promover visões homogeneizantes e estereotipadas do ser humano no plano ideológico das relações sociais, a sociedade tem favorecido uma onda crescente de individualismo e de competição (Khon, 1986; Lash, 1985; Morin, \& Prigogine, 2000; Velho, 1987), cristalizando maneiras específicas de pensar, sentir e agir.

Estas transformações se refletem nas instituições sociais, particularmente na família e na escola, pois estas atuam de forma mais direta na promoção de valores sociais, por meio do seu papel fundamental no desenvolvimento da visão de mundo, sociabilidade, afetividade e demais dimensões do desenvolvimento psicológico de crianças e adolescentes. No caso específico das instituições educacionais, estrutura e funções hierarquizam o espaço de tal modo que definem, por extensão, as formas de relação interpessoal, e assim vão promovendo valores, normas e princípios de acordo com suas propostas e concepções.

Estudos científicos voltados para a investigação de crenças e valores entre crianças, adolescentes e professores têm demonstrado que, na maioria dos contextos escolares, os professores têm orientado seus alunos a competirem entre si ou a serem individualistas (Branco, 2003, 2006; Crockenberg, \& Bryant 1979; Johnson,\& Johnson, 1989; Palmieri, 2003). Essa orientação, contudo, é geralmente implícita, ocorrendo poucas vezes por meio de incentivo explícito, direto do professor, já que as atitudes de um professor, seja na sala de aula ou em outros espaços da escola, são orientadas pelos seus conhecimentos sobre o mundo, e em especial por suas crenças, valores e orientações para objetivos (Branco, Mansini, \& Palmieri, 2012). Neste sentido as culturas coletiva e pessoal (e.g. Valsiner, 1994; 2000) do professor canalizam as suas práticas educativas, e têm importante impacto sobre o desenvolvimento dos alunos em suas múltiplas dimensões, incluindo-se aqui cognição, linguagem, afeto, socialização e até mesmo o desenvolvimento do self (Branco, 2006).

O mesmo se aplica às práticas sociais, interações e relações vivenciadas pelo indivíduo em outros contextos de desenvolvimento como a família, o grupo de pares etc., visto que é fundamentalmente pela participação em atividades sociais e fluxos interativos, caracterizados por uma determinada forma de participação preponderante (como competição, desprezo, opressão, ou então, ajuda, respeito, e cooperação) que se dá o desenvolvimento da criança, do adolescente e mesmo do adulto em determinadas trajetórias, em contraposição a outras trajetórias possíveis (Branco, 2006; Branco, Palmieri, \& Pinto; 2012; Rogoff, 2005; Valsiner, 1994).

O tema sobre os jogos cooperativos e a promoção da cooperação na educação infantil se inscreve nas discussões de um dos importantes aspectos do fenômeno da interdependência social, entendido na articulação entre padrões de interação social tais como cooperação, competição e individualismo e motivação (o conjunto de motivos, crenças e valores associados a estes padrões).

O objetivo deste artigo é examinar se a proposta dos jogos cooperativos tem potencial para professores promoverem ou inibirem a cooperação no contexto da educação infantil. Inicialmente apresentamos questões teóricas relativas ao tema do desenvolvimento da motivação e de padrões interativos associados à interdependência social. Em seguida discorremos sobre a proposta dos jogos cooperativos e, por último, relatamos a pesquisa empírica, analisando a proposta dos jogos cooperativos e defendendo por meio da psicologia científica tal proposta como essencial para professores da educação infantil promoverem interações cooperativas na educação infantil.

\section{Motivação e padrões de interação social na perspectiva sociocultural construtivista}

O termo sociocultural construtivista é usado em lugar do Co-Construtivismo, tendo em vista que a definição " $\underline{\mathrm{co}}$ " nem sempre comunica com clareza o papel central da dimensão sociocultural típica desta abordagem de base sócio-histórico-cultural (Valsiner, 1994, 2001). O termo "construtivista", associado ao conceito "sociocultural", porém não deve ser interpretado como referente a tendências neopiagetianas, mas sim como uma forma de expressar a relevância do princípio do sujeito "ativo", "co-construtivo" e "participante" de seu próprio desenvolvimento (como a utilização do termo "construtivo" tem sido empregada em autores como Maturana e Varela, 1995). E a dimensão histórica, nessa perspectiva, já está contemplada pelo construto "sociocultural", que remete à construção da cultura ao longo do tempo.

Conferindo um caráter direcional aos processos de desenvolvimento humano sempre orientado para o futuro, a perspectiva sociocultural construtivista focaliza, em especial, os elementos essenciais para a compreensão dos conceitos de internalização e de socialização como um processo bidirecional, o que auxilia a investigação de diferentes padrões de interação social. Neste sentido, a opção teórica aqui explicitada se dá pelo reconhecimento da dimensão conceitual e teórica da cooperação em termos de suas manifestações relativas à noção mais ampla de motivação social, que implica na consideração tanto da estrutura do contexto interativo (regras para o alcance de metas e objetivos), quanto da dinâmica efetiva das interações que se dão neste mesmo contexto (Valsiner, 1998). No entanto, dependendo da perspectiva teórica adotada, a cooperação pode ser enfatizada em diversos níveis de análise: perceptual, comportamental, interativa-relacional ou relativa às características estruturais-contextuais da interdependência social no contexto específico (Branco, 2001).

$\mathrm{Na}$ psicologia do desenvolvimento, por exemplo, a discussão teórica e conceitual da cooperação vem sendo 
feita no nível das ações ou comportamentos observáveis e caracterizados como pró-sociais (Eisenberg, 2002; Staub, 1989), visando atender às necessidades e ao bem-estar de outras pessoas (a generosidade, o altruísmo, sentimentos de empatia, a cooperação, a compaixão etc.). Alguns estudos na área, porém, associam o nível de análise comportamental ao campo motivacional e de caráter valorativo (Eisenberg, \& Mussen, 1989; Radke-Yarrow, \& Zahn-Waxler, 1991), destacando categorias mais amplas do comportamento pró-social, fazendo referência a motivos e metas a alcançar nas relações de interdependência humana.Os trabalhos de Johnson e Johnson (1989) destacam, além da estrutura, também o nível interacional para conceituar a cooperação, associada à noção de interdependência positiva. Para eles, a cooperação é fruto da coordenação de esforços de uns com os esforços de outros no alcance de metas comuns, a qual é favorecida em situações estruturadas de forma cooperativa.

Branco (1998) examina a cooperação e outras categorias relativas à motivação social a uma perspectiva sociocultural construtivista. Destaca a dimensão sistêmica e analítica no estudo de contextos específicos e/ou de atividades analisadas a partir de suas estruturas típicas, as quais podem facilitar ou dificultar a coordenação da conduta social dos indivíduos. Por exemplo, a convergência de objetivos entre os indivíduos pode facilitar a cooperação e a divergência de objetivos pode expressar a organização de contextos estruturados de forma competitiva. Sua concepção dinâmica dos contextos relacionais entre os indivíduos (frames), orientados por objetivos específicos, contempla a expressão do caráter ativo de participação dos indivíduos na construção conjunta das atividades. Ou seja, a autora enfatiza as possíveis transformações entre os frames (convergência, divergência, ambivalência e negociação), ao longo do fluxo das interações sociais.

Diante de um sistema aberto, motivação social "deve ser concebida como sistema que integra afeto e cognição de forma complexa e dinâmica"- plano das crenças e dos valores sociais - e, ao mesmo tempo, a motivação constitui-se e atua no contexto das práticas ou atividades concretas (Branco, 2006; Rogoff, 2005) - plano dos padrões de interação social. Assim, ao estudar o fenômeno da motivação social, a perspectiva sociocultural construtivista sugere o uso do termo Orientação para Crenças, o qual se relaciona aos conceitos de crenças e valores como construtos motivacionais de natureza semelhante. Crença implica no nível da experiência interacional imediata, afixando-se como um conceito mais próximo do convencional, advindo dos conselhos, hábitos e costumes que permeiam os discursos e as práticas culturais nos diferentes grupos sociais nos quais o indivíduo se desenvolve e valores como um caso especial de orientação para crença com tendência a possuir uma força maior ou poder, devido à carga afetiva mais densa presente na sua organização psicológica (Valsiner, Branco,\& Dantas, 1997). A dimensão motivacional e dinâmica do sistema de orientação para crenças está associada à ideia de orientação para objetivos uma vez que “... cada pessoa está frequentemente motivada por um amplo contexto de objetivos e metas, assumindo prioridades específicas que alteram, ao mesmo tempo, o fluxo dos relacionamentos entre a pessoa e o contexto" (Branco, 2001, p. 109).

No nível individual, a orientação para objetivos se desenvolve em uma maior ou menor complexidade, dependendo de inúmeros fatores, tais como as condições subjetivas da pessoa, as condições contextuais, e aspectos inerentes à vida social, entre outros. O que se quer dizer é que o caráter dinâmico das orientações para objetivos abre, no fluxo das interações sociais, espaço para que as ações dos indivíduos sejam coordenadas de forma cooperativa (objetivos comuns) ou de forma competitiva (objetivos excludentes). Processos de negociação podem ocorrer, sendo concebidos na construção de interações convergentes relativas a estruturas típicas diferentes (Branco,\& Fogel, 1996). Como resultado, por exemplo, orientações para objetivos inicialmente divergentes (incompatibilidade de objetivos - competição), podem se transformar em um padrão de interação convergente (compatibilidade de objetivos - cooperação) em função dos processos de negociação que surgem nas dinâmicas interativas (Branco, 2001; Palmieri,\& Branco, 2007).

Do ponto de vista metodológico, a abordagem microgenética (Siegler,\& Crowley, 1991) para análise das interações sociais é sublinhada, dado o potencial promissor para documentar a emergência das interações de forma detalhada e para avaliar os processos de co-construção de significados no tempo real (no aqui-e-agora). O nível microgenético de análise permite visualizar, por exemplo, as orientações para objetivos individuais, conduzindo a processos interacionais convergentes (por exemplo, a cooperação), divergentes (por exemplo, a competição), a processos de negociação ou à ambivalência (Valsiner, \& cols., 1997; Palmieri, \& Branco, 2004, 2007).Góes (2000) também explica a metodologia microgenética, a partir da matriz histórico-cultural, como aquela que trata de obter um relato minucioso dos eventos ao construir dados e ao recortar episódios interativos para análise do funcionamento das partes envolvidas (professor-alunos, por exemplo), das relações intersubjetivas e nas condições sociais da situação (Góes, 2000).

\section{O que são jogos cooperativos?}

Jogos cooperativos são exercícios para compartilhar, unir pessoas, despertar a coragem para assumir riscos, tendo pouca preocupação com o fracasso e o sucesso em si mesmos, mas sim uma fonte de prazer (Almeida, 2010; Brotto, 2000; Correia, 2006; 2007; Salvador, \& Trotte, 2001; Soler, 2003).

O precursor dos jogos cooperativos foi o educador americano Ted Lentz, cuja proposta foi sistematizada na década de 1950 nos Estados Unidos e difundida para outros países (Correia, 2006; Salvador, \&Trotte, 2001; Soler, 2003). Já o principal estudioso dos jogos cooperativos que pesquisou a relação entre jogo e sociedade foi Terry Orlick, pesquisador canadense da Universidade de Ottawa, nos 
anos 70 com a publicação do livro Vencendo a competição. Este livro tem servido de referência para qualquer trabalho sobre o tema. Nessa publicação o autor destaca a forte influência da exacerbação da competição no esporte - desde os gregos, na antiguidade - e a visão "esportivizante" da educação física escolar atrelada ao modelo competitivo das relações sociais e humanas que se estabeleceu na nossa sociedade capitalista, na tentativa de valorizar e promover a cooperação como paradigma fundamental das relações e ações humanas.

No Brasil, a experiência com os jogos cooperativos aconteceu por volta de 1980 no Estado de São Paulo, e hoje, de certa forma é conhecida em todo país a partir de diversas publicações de autores ligados à área da Educação e da Educação Física Escolar (Brotto, 2000; Correia, 2006, 2007; Soler, 2003, entre outros), tendo como pano de fundo as ideias de Orlik (1989).

Uma boa expressão dessa proposição é destacada no trabalho de Correia (2006, p. 43), a qual "representa a tentativa de valorizar uma estrutura cooperativa dos jogos em detrimento de outra competitiva, quando as características cooperativas são observadas em cada uma delas". Para ele, no jogo competitivo, as pessoas se sentem perdedoras e excluídas por falta de habilidade, pois a competição estimula a desconfiança e o egoísmo, cria barreiras, estimula o individualismo e o desejo que o outro sofra. Já o jogo cooperativo é divertido para todos e todos se sentem ganhadores; todos se envolvem de acordo com as habilidades; estimula o compartilhar e confiar; cria pontes entre as pessoas; não há exclusão, cada um auxilia com suas possibilidades para o grupo obter sucesso; ensina a ter senso de unidade e solidariedade; desenvolve e reforça os conceitos de nível AUTO (auto-estima, auto-aceitação); fortalece a perseverança frente às dificuldades; todos encontram um caminho para crescer e se desenvolver.

Há urgência na introdução dessas mudanças que se iniciam quando a estrutura dos jogos tradicionais é alterada em suas características de exclusão, agressividade, seletividade e exacerbação presentes em jogos competitivos para uma estrutura de jogos que sejam basicamente pautados na cooperação, na aceitação, no envolvimento e na diversão. Nestes termos, o confronto entre adversários é eliminado e os participantes passam a jogar uns com os outros e não uns contra os outros, visando o alcance de um objetivo comum (cooperação).

Orlik (1989) propõe uma categorização dos Jogos Cooperativos, que serve para orientar o professor a reconstruir e adaptar jogos a uma concepção não competitiva ou cooperativa, sendo ela: Jogos cooperativos sem perdedores (são jogos plenamente cooperativos, onde todos jogam juntos e não há perdedores);Jogos cooperativos de resultado coletivo (existe divisão em duas ou mais equipes, mas o objetivo do jogo só é alcançado com todos jogando juntos); Jogos cooperativos de inversão (envolvem equipes, mas todos os jogadores trocam de equipe a todo instante, dificultando reconhecer vencedores e perdedores);Jogos semi-cooperativos (envolvem duas ou mais equipes e o ob- jetivo do jogo só é alcançado quando há cooperação entre os participantes do grupo (intra-grupos) e competição entre as equipes (inter-grupos).

Por outro lado, é importante destacar que os jogos cooperativos representam uma "ressignificação crítica do esporte e do significado da competição" (Oliveira, 2002, p.6), pois dão ênfase ao significado central do esporte que é marcar pontos e não sofrer por não tê-los marcado, o que leva à percepção de fracasso e derrota, e pode causar incompatibilidade de objetivos e rivalidade.

Seguindo essa linha de raciocínio, a proposta dos Jogos Cooperativos evoca a reflexão sobre o tipo de relação que temos vivenciado em nossa sociedade como uma forma de superar tendências individualistas e competitivas que perpetuam a desigualdade social. Os autores da área da educação física escolar sustentam a possibilidade de vivermos numa sociedade capaz de promover a cooperação, apontam a necessária mudança de concepções e práticas que levem a novas aprendizagens socioeducativas. Cabe à escola, como um contexto sociocultural privilegiado para a constituição de modelos de conduta social e de valores humanos e, ao educador como um agente de mudança, possibilitar a integração de espaços de cooperação, que favoreçam um desenvolvimento pleno, flexível, sadio e diversificado aos seus alunos, na direção de valores democráticos e de autonomia associados à solidariedade.

\section{Método}

A pesquisa foi realizada em um Centro Filantrópico de Educação Infantil (CEI) na cidade de Londrina - PR. Participaram do estudo duas turmas de crianças (24 crianças) entre 4 e 6 anos e duas professoras, aqui denominadas de professora 1 (P1) e professora 2 (P2). P1 tinha 10 alunos e P2 14.Os critérios de escolha das professoras e das crianças se relacionaram ao interesse das professoras em participar de atividades referentes a Jogos Cooperativos e introduzir essa atividade juntamente com as demais atividades do dia a dia das crianças na escola. Nesse sentido, outras professoras poderiam ter participado das atividades de Jogos Cooperativos e outras crianças também, já que não importa a faixa etária das crianças para participarem de jogos organizados cooperativamente (Soler, 2003). Os procedimentos foram desenvolvidos mediante duas etapas. $\mathrm{Na}$ primeira etapa foram realizados dois encontros de formação com as duas professoras para orientá-las tanto na compreensão do que é cooperação quanto para auxiliá-las na escolha de jogos, de acordo com uma concepção não competitiva ou cooperativa para aplicar junto às crianças a partir das sugestões de jogos contidas no livro "Jogos cooperativos na educação infantil” (Soler, 2003). Essa primeira etapa ocorreu em dois sábados consecutivos, no período da manhã, nas dependências do próprio Centro de Educação Infantil, cujo tempo total de duração foi de oito horas. Em acréscimo, para a realização dessa primeira etapa, uma apostila foi elaborada pela pesquisadora, contendo, de forma explicativa, o 
conceito de cooperação, a definição e a categorização dos jogos cooperativos (Orlik, 1987), suas características, comparações de situações cooperativas e competitivas e enfatizado o papel mediador do professor na condução desses jogos, salientando seu caráter socializador para promover a cooperação entre as crianças.

Logo após os dois encontros de formação, e como forma de servir a uma avaliação da primeira etapa, na segunda etapa cada uma das professoras escolheu um jogo cooperativo - tal como sugerido por Soler (2003) - para promover a cooperação com as suas crianças. No dia e horário combinado com as professoras, a pesquisadora se dirigiu ao Centro de Educação Infantil para realizar a vídeo gravação dos jogos cooperativos que elas promoveriam. A professora 1 (P1) escolheu promover o jogo cooperativo "Pipoca Melada", e a professora 2 (P2) "Caiu na rede é amigo", ambos classificados como "sem perdedores", de acordo com a classificação dos jogos cooperativos (Orlik, 1989). A seguir, as professoras convidaram as crianças para participarem do jogo que seria gravado em vídeo. As crianças se dirigiram às professoras e estas iniciaram a atividade do jogo que escolheram. O material vídeogravado foi transcrito na íntegra, resguardando-se a identidade dos participantes (foram atribuídos nomes fictícios às crianças e denominação numeral para as professoras), segmentado em episódios interativos e tematizados, considerando a natureza das interações e o tempo de duração de cada episódio. A análise dos dados foi realizada, portanto, através da abordagem microgenética, de acordo com Siegler e Crowley (1991) e Góes (200, p. 9 ), pois "dadas as demandas de registro implicadas, essa análise é associada ao uso de videogravação, envolvendo o domínio de estratégias para a filmagem e a trabalhosa atividade de transcrição".

Em termos éticos, a pesquisa foi aprovada pelo Comitê de Ética em Pesquisa envolvendo Seres Humanos da Universidade Estadual de Londrina-PR (Registro CONEP 268) em 11/02/2011, sendo o parecer de aprovação de $n^{\circ}$ $274 / 2010$.

\section{Resultados}

O jogo escolhido por P1 ("Pipoca Melada") começou com o pedido para que as crianças pulassem como se fossem pipocas. Quando duas pipocas (crianças) entravam em contato uma com a outra, elas deviam ficar juntas (grudadas). Uma vez grudadas, as crianças deveriam continuar a procurar outras "pipocas", até que todas formassem uma grande bola de pipocas. No jogo cooperativo "Caiu na rede é amigo", conduzido por P2, um jogador foi sorteado para começar a brincadeira. Esse jogador corria em perseguição a todos os outros. O amigo que era apanhado deveria dar-Ihe as mãos e unidos, partirem à conquista de outros amigos. Os novos amigos incorporavam-se ao grupo dos perseguidores, unindo as mãos em fileira, que era a rede. As crianças deveriam correr em perseguição aos que estavam dispersos e os fugitivos tentariam escapar. O jogo só terminaria quando uma grande rede fosse formada com todos os jogadores. O jogo cooperativo "Pipoca Melada" conduzido pela professora 1 teve como tempo de duração total nove minutos e 23 segundos e o jogo "Caiu na rede é amigo" instruído pela professora 2, 11 minutos e 45 segundos. Apresentamos a seguir seis sequências interativas dos jogos videogravados (três episódios orientados pelas professoras) analisadas em nível microgenético para ilustrar o padrão de interação promovido pelas duas professoras junto às crianças. Os episódios selecionados dizem respeito a três momentos que configuraram o processo de condução dos jogos por ambas as professoras. O primeiro momento se refere às instruções das regras para as crianças participarem do jogo, o segundo diz respeito ao desenvolvimento do jogo e o terceiro ilustra a finalização do jogo pelas professoras.

\section{Seqüências do Jogo Cooperativo "Pipoca Melada" promovido pela Professora 1}

\section{Episódio 2: $O$ que é Cooperação?}

Duração do episódio 1': 52"

$\mathrm{P} 1$ explica às crianças como a brincadeira vai funcionar: - Hoje nós vamos brincar daquela brincadeira pipoca melada. Que brincadeira é essa? É uma brincadeira...

E algumas crianças respondem animadamente: - Cooperativa.

P1 pergunta: - O que é cooperativo para vocês?

Uma criança responde: - Tem que brincar junto.

P1 balança a cabeça positivamente e parafraseia:-

Tem que brincar junto e o que mais?

E a mesma criança continua:- Tem que ser amigo.

P1 reitera dizendo: - Tem que ser amigo.

Dando um passo na direção de Raul, P1 pergunta: Você sabe Raul o que mais?

Raul não responde. $\mathrm{P} 1$ responde no lugar da criança: - Tem que respeitar o amiguinho, não é verdade?

E outra criança ao lado de Raul responde em tom animado: - É, tem que brincar com o amiguinho.

P1 afirma animada: - Issooo!

\section{Episódio 4: Do ladinho ou Separadinho?}

Duração do episódio 43"

P1 diz em tom explicativo: - Todo mundo vai levantar, levanta todo mundo. Um vai ficar do ladinho do outro, um do ladinho, todo mundo do ladinho. Mas P1 continua, dizendo:- Pode ficar um pouquinho separado! Todo mundo! Todo mundo separadinho.

P1 começa a separar as crianças direcionando-as para os lados. Vendo que duas crianças estão de mãos da- 
das, diz: - O Luis e João podem soltar as mãozinhas! Aí nós vamos erguer os bracinhos, lá no alto...

Todos levantam suas mãos e P1 continua: - $E$ todo mundo vai começar a pular e contar, contar até três! Tá?

Uma das crianças pergunta: - Até três?

$\mathrm{P} 1$ responde: - Isso! Aí nós vamos ter que ir pulando, pulando, pulando até um ficar de frente para o outro, e todo mundo ir ficando beeem juntinho igual pipoca lá na panela, tudo bem?

Alguns respondem: - Tá!

- Então vai... um, dois, três e já!

\section{Episódio 5: O Jogo Cooperativo}

Duração do episódio 2':15"

$\mathrm{P} 1$ e as crianças começam a pular. Uma das crianças começa pulando em direção à $\mathrm{P} 1$ e estende suas mãos para que ela as segure. P1 segura as mãos da criança e diz gritando: - Todos pulando! Vai, vai. Vamos, todo mundo pulando bem juntinho.

Algumas crianças vão se grudando e gritando umas para as outras: - Aqui, aqui, vem aqui!

P1 diz em tom de ordem: - Tem que encontrar o amiguinho! Vai, vamos pulando juntinho. Vai Raul, vamos lá. Com alguém.

P1 olha para a criança que está segurando suas mãos e diz: - Vamos lá, vamos encontrar o Raul.

Elas se aproximam de Raul e P1 diz: - Vem Raul, vamos lá igual pipoca.

P1 segura sua mão e continua pulando junto com as crianças. As crianças se juntam espontaneamente e começam a pular em círculos segurando as mãos em roda. P1 diz se direcionando para uma criança: - Vai com a Julia, vamos pegar a Julia. Pula, pula, pula! Raul segura a mão da Julia.

Após isso, P1 se dirige a outra criança, dizendo:

- Vamos buscar os amiguinhos aqui.

$\mathrm{P} 1$ e as crianças vão pulando ao encontro das outras. Duas crianças não estão de mãos dadas e $\mathrm{P} 1$ faz um pequeno gesto com a mão para que segurem as mãos, fechando o círculo. Quando todas as crianças estão juntas P1 anuncia o término do o jogo:

- Aê!!!

Durante o jogo cooperativo promovido por $\mathrm{P} 1$, observamos regras e instruções tipicamente cooperativas na condução deste. Desde o início ela deixou bem clara a regra da "ajuda" e sua real necessidade, complementada por falas como "tem que brincar junto, ser amigo, ajudar e respeitar o amigo...".

Podemos dizer que, apesar de P1 muitas vezes responder no lugar das crianças, as crianças interpretaram a sugestão de "ajuda" como indicação de regra para participar do jogo ("- É, tem que brincar com o amiguinho"), tornando a noção de "não agir sozinho", sinônimo de requisito e capacidade para participar do jogo que ela estava propondo.
Podemos dizer, então, que o significado do termo "ajuda" passou a ter, assim, uma conotação positiva e motivadora para as crianças participarem do jogo que $\mathrm{P} 1$ iria promover.

$A$ atuação de $\mathrm{P} 1$, portanto, serviu como influência canalizadora das interações desenvolvidas durante o jogo "Pipoca melada", por meio da indução à cooperação, já que as crianças precisavam cooperar umas com as outras para participarem da atividade. P1 estruturou uma atividade (sem perdedores) na qual as crianças tinham que alcançar metas congruentes fazendo prevalecer a motivação para cooperar, o que favoreceu interações conjuntas entre os participantes (Branco, 2001; Branco \&Valsiner, 1997).

\section{Seqüências do Jogo Cooperativo "Caiu na rede é amigo" promovido pela professora 2:}

\section{Episódio 2 - Explicando o significado de "rede" no jogo}

Duração do episódio: 52'

P2 indaga:- Por que a nossa brincadeira se chama assim, Caiu na rede é amigo? O que é uma rede?

Uma das crianças, gesticulando com as mãos, responde:- Ela é cheia de fio colorido.

P2 continua questionando as crianças:- É um monte de fiozinho. E ficar separado vai ficar legal?

Todas as crianças respondem juntas: - Não!!

P2 pergunta: - Não, porque o que pode acontecer? Isso, se vocês sentarem... Isso, se alguém sentar na rede com buraco o que vai acontecer?

Algumas crianças respondem:- Vai cair!

P2 continua perguntando em tom de entusiasmo:Então?E para nossa rede ficar forte o que precisa acontecer?

Uma criança responde:- Tem que pegar o amiguinho e deixar ele te pegar.

P2 concorda e continua perguntando:- Isso, isso... Tem que ficar de mãozinha dada bem junto.

Uma criança interrompe P2 e diz em tom alto de voz:É de deixar a mãozinha dada.

P2 concorda com a criança balançando a cabeça afirmativamente, dizendo:- De mãos dadas, muito bem!

\section{Episódio 4: Vamos brincar? Interrompendo o jogo}

Duração do episódio: 1': 30"

P2 convida as crianças: - Vem todo mundo aqui pertinho de mim.

As crianças se levantam rapidamente e correm ao encontro de P2 que diz em tom de explicação: - Eu vou ficar de mãos dadas aqui com o Luis [pegador] para a gente poder começar. E vou falar: um, dois, três e...

As crianças respondem animadas: - Já!!

P2 fala em tom mais sério: - Calma aí! 
P2 volta a contar, mas agora um pouco mais devagar:- Um, dois, três e... espera só um minutinho. A nossa brincadeira vai ser realizada só aqui na grama, tá?

As crianças que haviam começado a correr param e prestam atenção às instruções. P2 continua a falar em tom explicativo: - No pátio nem na escada não. Combinado?

As crianças respondem afirmativamente e P2 diz:Então pode começar.

\section{Episódio 12: Finalizando o jogo}

\section{Duração do episódio: 32"}

P2 instrui as crianças para fecharem a roda e para ficarem de mãos dadas, mesmo considerando que algumas crianças não estavam de mãos dadas formando a rede. Ela pergunta em tom de entusiasmo:- Nós conseguimos?

O grupo responde animadamente em coro:- Sim!

- Fizemos uma rede de amigos?- Sim!

P2 pergunta com animação:- Foi legal?

$\mathrm{E}$ as crianças respondem em tom desanimado: - Foi!

- Todo mundo cooperou e deixou pegar na mãozinha?

Algumas crianças dizem: - Sim!

P2 diz em tom de animação:- Parabéns para vocês, então!

Todos começam a bater palmas, gritando animadamente.

No caso de P2, o jogo "Caiu na rede é amigo" teve início com uma estrutura cooperativa, com a professora procurando incentivar as crianças a entenderem o significado do termo rede (fazendo alusão ao jogo que iria promover), com as crianças respondendo suas incitações "Tem que pegar o amiguinho e deixar ele te pegar" (...) é de deixar a mãozinha dada. Contudo, durante o jogo a estrutura cooperativa vai se transformando pelas próprias intervenções/interrupções de $\mathrm{P} 2$, em uma atividade desmotivadora coordenada por ela. Tanto é assim que em um dos episódios analisados (episódio 4), apesar de as crianças demonstrarem motivação para participar da construção conjunta da atividade ("Já"), P2 instruiu "Calma aí!". Tudo indica que P2 acabou por suprimir as motivações das crianças para cooperarem entre si, preocupando-se mais em enfatizar as regras do jogo e menos no jogo que aconteceria em "grupo". Essa orientação de P2 limitou as chances das crianças de participar de modalidades cooperativas na construção do jogo, levando-as a desenvolver um padrão de interação independente em relação à $\mathrm{P} 2$, à espera de que a atividade terminasse. Tanto é assim que, em função dessa orientação, P2 decide encerrar o jogo abruptamente e independentemente da participação ou não das crianças, que acabam por concordar com as perguntas de P2. (Nós conseguimos? - Sim! Foi legal? - Foi! Todo mundo cooperou e deixou pegar na mãozinha? - Sim! Parabéns para vocês então!).

\section{Discussão}

Os principais resultados obtidos a partir das análises das interações nos dois jogos cooperativos organizados e promovidos pelas duas professoras serão aqui destacados para possibilitar reflexões à luz da teoria e enfocar conceituações, contradições e coerências encontradas na prática das docentes. Os dados coletados mostram que em ambos os jogos cooperativos "Pipoca Melada" e "Caiu na rede é amigo", as professoras estavam orientadas pelo objetivo de fazer com que as crianças entendessem o significado do que é cooperar. Nesse aspecto, não podemos afirmar que as crianças internalizaram, de fato, o significado de cooperar a partir das instruções das professoras, mas podemos afirmar sobre as orientações para crenças e objetivos destas em relação à cooperação ao promover os jogos com as crianças. Da mesma forma, durante os jogos, as professoras também se orientaram por assegurar-se de que as crianças entendessem as regras do jogo para participar da brincadeira e se preocuparam em encorajá-las a colaborarem umas com as outras. Nesse sentido, podemos dizer que as orientações para crenças e objetivos das duas professoras carregavam um sentido de cooperação, no qual vencer o jogo não era o principal objetivo dos participantes.

Os seis episódios analisados mostraram orientações para crenças e objetivos das professoras revelando que: a) em uma situação de cooperação, as crianças deveriam contar com a ajuda dos colegas para participar do jogo; b) é muito importante segurar nas mãozinhas dos colegas para participar do jogo; c) é mais importante respeitar o amigo e brincar junto do que brincar de forma independente. Com essas orientações para crenças e objetivos comunicadas às crianças, as professoras revelaram indução à cooperação durante as instruções oferecidas para a realização dos jogos cooperativos, garantindo, inclusive, que a instrução dúbia que marcou o episódio 4 ("juntinho ou separadinho"), conduzido por P1, por exemplo, não interferisse no funcionamento do jogo em termos da promoção de processos interativos convergentes (cooperação), tendo $\mathrm{P} 1$ sempre incentivado e estimulado as crianças a darem as mãos e a realizarem juntas a brincadeira (episódio 5).

Portanto, na análise dos episódios selecionados verificou-se grande coerência entre a proposta original (para que as professoras promovessem uma atividade de jogo cooperativo entre as crianças) e os jogos efetivamente promovidos por elas. Tanto as atividades quanto as instruções/ orientações de ambas as docentes estiveram voltadas para a promoção da cooperação. Isso, claramente, nos leva a concluir que ambas as professoras entenderam o significado do termo "cooperar", tal como foi explorado na primeira etapa e promovido na segunda.

Em outras palavras, as crianças foram orientadas pelas professoras por objetivos congruentes (cooperação), os quais expressaram o processo de canalização cultural da cooperação na construção conjunta dos jogos conduzidos. Além disso, ainda que o espaço dos jogos servisse como evidência de interações ambivalentes, estas foram se 
transformando em interações convergentes (cooperação) ao longo do fluxo das relações entre as professoras e as crianças. Assim, a partir dos episódios analisados podemos dizer que as duas professoras explicitaram para as crianças o significado e a importância de cooperar durante a condução dos jogos (Branco,\& Mettel, 1985; Palmieri,\& Branco, 2007; Branco, Pinto,\& Palmieri, 2012).

Enfim, a análise microgenética das interações professoras-crianças revelou a importância da proposta dos jogos cooperativos para promover a cooperação, na medida em que permitiu a análise das interações sociais de forma detalhada, ao longo do fluxo contínuo e complexo de comunicação e metacomunicação entre as professoras e as crianças (Branco, \& Valsiner, 1997), caracterizada pela contínua co-construção de orientação para objetivos. Durante a condução dos jogos cooperativos as professoras mostraram que a cooperação é fruto da coordenação de esforços de uns com os esforços dos outros no alcance de metas comuns, o que é favorecido em situações tipicamente estruturadas de forma cooperativa.

\section{Conclusão}

A experiência empírica relatada deixa bem clara a importância do tipo de instrução inicial que é oferecida pelas professoras, que se preocuparam em incentivar o entendimento das regras para as crianças participarem da atividade (Branco, \&Metell, 1985; Palmieri, \& Branco, 2007). Deixou claro também que a proposta dos jogos cooperativos estimula/incentiva/motiva a promoção da cooperação na educação infantil, a qual favorece a participação das crianças em atividades lúdicas de cooperação, visando o alcance de objetivos comuns, o que pode contribuir para que venham a construir valores ligados à progressiva autonomia e independência para coordenar suas ações com a dos outros. Tal proposta também possibilita ao professor compartilhar com os alunos seus objetivos e metas, podendo melhor explorar as configurações motivacionais facilitadoras de modalidades construtivas de interdependência social.

Uma das proposições que fazemos é a necessidade urgente da estruturação de projetos de orientação continuada às professoras, relacionados ao estudo e promoção dos valores sociais (ou humanos) são promovidos nos contextos educacionais, sendo a proposta dos jogos cooperativos um recurso auxiliar importante para o alcance desse objetivo. Tal projeto envolveria discussões sobre suas concepções de cooperação, competição, individualismo, socialização, interação, enfim, processos de desenvolvimento humano com o objetivo de fomentar novas ideias, reflexões e análises das atividades promovidas por professores da educação infantil em suas interações com as crianças.

\section{Referências}

Almeida, T. P. (2010). Brincar cooperativo: Vivências lúdicas de jogos não competitivos. São Paulo: Editora Vozes.
Branco, A. U. (1998). Cooperation, competition and related issues: A co-constructive approach. Em M. C. Lyra \& J. Valsiner (Orgs.), Child development within culturally strutured environments. Vol 4: Construction of psychological processes in interpersonal communication. Norwood, N. J.: Ablex Publishing Corporation.

Branco, A. U. (2001). Contextual, interactional and subjective dimensions of cooperation and competition: A co-constructivist analysis. Em S. Chaiklin (Org.), The theory nd practice of culturalhistorical psychology (pp. 107-123). DK: Aarhus University Press.

Branco, A. U. (2003). Social development in social contexts: cooperative and competitive interaction patterns in peer interactions. Em J. Valsiner, \& K.J. Connolly (Orgs.), Handbook of developmental psychology. London: Sage.

Branco, A. U. (2006). Crenças e práticas culturais: Co-construção e ontogênese de valores sociais. Pro-Posições, 17 (2), 139-155.

Branco, A. U., \& Fogel, A . (1996). Metacommunication as a source of indeterminism in relationship development. Em A. Fogel, M. Lyra, \& J. Valsiner (Orgs.), Dynamics and indeterminism in developmental and social process. New Jersey: Lawrence Erlbaum Associates.

Branco, A. U.,\& Mettel, T. P. L (1995).O processo de canalização cultural das interações criança-criança na pré-escola. Psicologia: Teoria e Pesquisa, 11 (1), 13-22.

Branco, A. U., \& Valsiner, J. (1997). Changing methodologies: A co-constructivist study of goal orientation in social interaction. Psychology and Developing Societies, 9 (1), 35-64.

Branco, A. U., Mansini, R. G. P., \& Palmieri, M. W. (2012). Cooperação e promoção da paz: valores e práticas culturais em contextos educativos. Em A. M. C. U. Branco, \& M. C. S. L. Oliveira (Orgs.). Diversidade e cultura da paz na escola: contribuições da perspectiva sociocultural (pp. 95-123). Rio Grande do Sul: Editora Mediação.

Branco A. U.; Palmieri, M. W., \& Pinto, R. G. (2012). Cultural Practices and Values Constructions: The development of competition and individualism within societies. Em A. U. Branco, \& J. Valsiner (Orgs.), Cultural Psychology no human values (pp. 31-62). Charlotte, NC, USA: Information Age Publishing.

Brotto, F. O. (2000). Jogos Cooperativos: Se o importante é competir, o fundamental é cooperar. Santos: Renovada.

Correia, M. M. (2006). Trabalhando com Jogos Cooperativos: Em busca de novos paradigmas na educação física. Campinas: Papirus.

Correia, M. M. (2007). Jogos Cooperativos e Educação Física escolar: Possibilidades e desafios. Revista Digital, 12 (107). 
Crockenberg, S., \& Bryant, B. (1979). Socialization: The 'implicit curriculum' of learning environments. Journal of Research and Development in Education, 12 (1), 69-78.

Eisenberg, N. (2002). Empathy-related emotional responses, altruism and their socialization. Em R.J. Davidson, \& A. Harrington (Orgs.), Visions of compassion (pp.131-164).New York: Oxford University Press.

Eisenberg, N., \& Mussen, P. H. (1989). The roots of prosocial behavior in children. New York, NY: Cambridge University Press.

Góes, M. C. R. (2000). A abordagem microgenética na matriz histórico-cultural: Uma perspectiva para o estudo da constituição da subjetividade. Cadernos CEDES, 20 (5), 9-25.

Johnson, D. W., \& Johnson, R. T. (1989). Cooperation and competition: Theory and research. Edina, Minnesota: Interaction Book Company.

Khon, A. (1986). No contest: the case against competition. Boston, M A: Houghton Mifflin Company.

Lash, C. (1985). O mínimo eu: a sobrevivência psíquica em tempos difíceis. São Paulo, SP: Editora Brasiliense.

Maturana, H., \& Varela, F. (1995). A árvore do conhecimento: as bases biológicas da compreensão humana. São Paulo: Editora Palas Athena.

Morin, E.,\& Prigogine, I. (2000). A sociedade em busca de valores. Lisboa: Instituto Piaget.

Orlik (1989). Vencendo a competição. São Paulo: Círculo do Livro.

Oliveira, D. T. R. (2002). A competição do esporte: Uma vitória ou derrota para a educação física. Anais do VI Encontro Fluminense de Educação Física Escolar (pp. 5-8). Niterói: Departamento de Educação Física da Universidade Federal Fluminense.

Palmieri, M. W. A. (2003). Cooperação, competição e individualismo: Uma análise microgenética de contextos de desenvolvimento na pré-escola, Tese de Doutorado, Universidade de Brasília, DF.

Palmieri, M. W., \& Branco, A. U. (2004). Cooperação, competição e individualismo em uma perspectiva sócio-cultural construtivista. Psicologia Reflexão \& Crítica, 17 (2), 189-198.

Palmieri, M. W., \& Branco, A. U. (2007). Educação infantil, cooperação e competição: Análise microgenética sob uma perspectiva sociocultural. Psicologia Escolar e Educacional, 11 (2), 365-378.

Radke-Yarrow, M., \& Zahn-Waxler, C. (1991). The role of familial factors in the development of prosocial behavior: Research findings and questions. Em D. Olweus. J. Block, \& M. Radke-Yarrow (Orgs.), Development of antisocial and prosocial behavior. New York, NY: Academic Press.
Rogoff, B. (2005). A natureza cultural do desenvolvimento humano. Porto Alegre: Artmed.

Salvador, M. A. S., \& Trotte, S. M. S. (2001). Jogos Cooperativos: Uma Estratégia Essencial da Cultural Corporal nas Escolas Públicas. Anais do V Encontro Fluminense de Educação Física Escolar (pp. 69-72). Niterói: Departamento de Educação Física da Universidade Federal Fluminense.

Siegler, R. S., \& Crowley, K. (1991).The microgenetic method. American Psychologist, 46 (6), 606-620.

Soler, R.(2003). Jogos cooperativos para educação infantil ( $2^{\mathrm{a}}$ ed.). Rio de Janeiro: Sprint.

Staub, E. (1989). Individual and societal (group) values in a motivational perspective and their role in benevolence and harm doing. Em N. Eisenberg, J. Reykowski, \& E. Staub (Orgs.), Social and moral values (pp. 45-57). Hillsdale, NJ: Lawrence Erlbaum Associates.

Valsiner, J. (1989). Human development and culture: The social nature of personality and its study. Lexington, MA: Lexington Books.

Valsiner, J. (1994). Culture and human development: A coconstructive perspective. Em P. Van Geert, \& L. Mos (Orgs.), Annals of Theoretical Psychology (Vol. 10). New York: Plenum.

Valsiner, J. (1998). The guided mind: A sociogenetic approach to personality. Cambridge, MA: Harvard University Press.

Valsiner, J. (2000). Culture and human development. London: Sage.

Valsiner, J. (2001). Comparative study of human cultural development. Madrid: Fundación Infancia y Aprendizaje.

Valsiner, J., Branco, A. U.,\& Dantas, C. (1997). Co-construction of human development: Heterogeneity within parental belief orientations. Em: J. E. Grusec, \& L. Kuczynski (Orgs.), Parenting and children's internalization of values (pp. 283-304). New York: Wiley.

Velho, G. (1987). Individualismo e cultura. Rio de Janeiro, RJ: Zahar. 
Sobre a autora:

Marilicia Witzler Antunes Ribeiro Palmieri (marilicia@uel.br)

Doutora em Psicologia pela Universidade de Brasília - DF 